Daimon. Revista Internacional de Filosofía, Suplemento 5 (2016), 611-620

ISSN: 1130-0507 (papel) y 1989-4651 (electrónico)

http://dx.doi.org/10.6018/daimon/268791

\title{
Cuerpos feministas en revolución
}

\author{
Feminist bodies in revolt
}

ELVIRA BURGOS DÍAZ*

\begin{abstract}
Resumen: Incidiendo en la pérdida de las utopías revolucionarias modernas; en el motivo y las consecuencias de la quiebra de las narrativas culturales y políticas que organizaban nuestro mundo y que ya no pueden mantener su carácter legitimador, me propongo reflexionar sobre las políticas feministas del cuerpo. Impulsadas por el deseo postrevolucionario de transformación, trabajan Wendy Brown y Judith Butler afirmando el carácter constitutivo de la vulnerabilidad y denunciando desde ahí las políticas que distribuyen la vulnerabilidad diferencialmente, según criterios de desigualdad y subordinación: definen la masculinidad por su invulnerabilidad y la feminidad por una vulnerabilidad exacerbada. Estas dinámicas son resistidas, alteradas, dislocadas por los cuerpos feministas en revolución.

Palabras clave: políticas, feminismos, cuerpos, deseos, igualdad, libertad
\end{abstract}

\begin{abstract}
Taking as its point of departure the demise of the modern revolutionary utopias, the causes and consequences of the breakdown of the cultural and political narratives that organized our world and that can no longer fulfill their legitimizing function, this article reflects on the role played by feminist bodily politics. Driven by the post-revolutionary desire of transformation, Wendy Brown and Judith Butler regard vulnerability as constitutive and denounce the politics of inequality and subordination that result in a differential distribution of that vulnerability: for instance, by characterizing masculinity as invulnerable and femininity as extreme vulnerability. These dynamics are opposed, altered, disrupted by the feminist bodies in revolt. Keywords: policies, feminisms, bodies, desires, equality, freedom
\end{abstract}

Desde una perspectiva genealógica y a través de metáforas espaciales más que temporales, Wendy Brown reflexiona sobre lo político. Nos acerca un modo de pensar y de hacer política feminista en la que el cuerpo en su vulnerabilidad y precariedad cobra una dimensión especialmente relevante. Ella subraya, como también Judith Butler, la asociación de la invulnerabilidad con la masculinidad y la de la vulnerabilidad acrecentada con la feminidad; de modo que en este marco masculinista dominante, la feminidad y la masculinidad se producen a través de la distribución diferencial de la vulnerabilidad.

Fecha de recepción: 09/06/2016. Fecha de aceptación: 17/07/2016.

* Profesora de Filosofía en la Universidad de Zaragoza. Correo electrónico: eburgos@unizar.es. Líneas de investigación: Pensamiento feminista y Filosofía del cuerpo. Publicaciones recientes: "Arriesgar el propio ser: Nietzsche, Foucault, Butler”, en: D. Pérez Chico y A. García Ruiz (eds.): Perfeccionismo: Entre la ética política y la autonomía personal, Zaragoza, Prensas de la Universidad de Zaragoza, 2014, pp. 117-137; “Traducción cultural feminista”, en: S. París Albert e I. Comins Mingol (eds.): Humanismo global. Derecho, religión y género, Sevilla, Editorial Thémata, 2016, pp. 217-228. 
En La política fuera de la historia, Brown pone de relieve cómo en las últimas décadas el liberalismo va siendo horadado por el encuentro con sus múltiples otros. El liberalismo se organiza y se sostiene en exclusiones, de clase, raza, género, sexualidad, cuanto menos. El sujeto sobre el que se articula se ha puesto en evidencia; es un sujeto blanco, burgués, masculino, heterosexual, que pone seriamente en riesgo la promesa liberal de la igualdad y justicia universales. El relato que declaraba la progresiva ampliación y extensión de la igualdad y de la emancipación a sectores cada vez más amplios de la población ha dejado de ser creíble. Defender que la noción de persona abstracta, desprovista de las características corporales y sociales específicas que nos constituyen, nos puede conducir hacia la liberación de todo tipo de subordinación, se manifiesta ya como imposible. Esa noción de persona ejerce la dominación sobre las categorías excluidas encubriendo su lógica de poder. Al desvelarse lo que escondía, se rompe el ideal que prometía. Ante este derrumbe del formalismo universalista del liberalismo y de su concepción progresista y teleológica de la historia, Brown afirma que se pueden formular objetivos y estrategias parciales y provisionales, en contra de la desigualdad, de las exclusiones, de la falta de libertad:

¿Qué otra cosa, aparte de la anarquía o la caída libre, puede esperarse de la desestabilización de las narraciones políticas o culturales que constituyen nuestro mundo? Cuando las premisas fundamentales de un orden dado comienzan a erosionarse, o simplemente empiezan a ser cuestionadas, ¿qué formaciones políticas emergen -y qué ansiedades, tensiones u obstáculos traen consigo? (Brown, 2014, 19).

Los relatos políticos imperantes en la modernidad, los ideales del liberalismo, han sido cuestionados en profundidad aunque de algún modo persisten como horizonte en nuestra sociedad contemporánea. El análisis de la manera en la que permanecen, incluso en su confusión y desorientación, y la reflexión sobre las consecuencias políticas de su supervivencia, es tarea que se propone Brown desde una orientación genealógica, en el sentido nietzscheano $\mathrm{y}$ foucaultiano.

Esta genealogía se distancia tanto de la metafísica como de la historia teleológica convencional al dirigirse hacia la desnaturalización de aquello que se nos presenta como ya dado de antemano, y dotado de una fuerte fundamentación. La crítica genealógica desfundamenta los supuestos fundamentos, cuestiona los significados que se presentan como inmutables; incide en desvelar la contingencia de nuestro pasado, que el presente no se sostiene en el suelo sólido del pasado. Se resaltan no las líneas rectas, rígidas, inevitables, gobernadas por el principio de causalidad; al contrario, se iluminan las grietas, las quiebras, las discontinuidades, las inestabilidades. Rememorando a Foucault, Brown afirma la potencia analítica de la imagen geológica, más certera que la imagen evolutiva. La perspectiva genealógica no se centra en la linealidad, no da protagonismo a la temporalidad pura, a una temporalidad que, paradójicamente, se impone "intemporalmente", como si situara su valor fuera del tiempo, deteniéndolo, inmovilizándolo; la genealogía piensa a través de capas que se acumulan heterogéneamente, y con ello dota al tiempo de especial densidad, en tanto lo concibe en relación con el espacio. La historia como campo de fuerzas espacio-temporales, se abre al fragmento, a la dispersión de lo incoherente y múltiple. Para la acción crítica feminista, la mirada genealógica es particularmente poderosa porque alienta e impulsa la agitación 
transformadora, porque nos abre la posibilidad ilusionante de un futuro no masculinista. En Brown cobra una relevancia luminosa, feminista, la herramienta genealógica:

La genealogía reorienta la relación de la historia con la posibilidad política: aunque el campo actual de la posibilidad política se ve limitado por sus historias, estas historias son narraciones de improbable, inconstante y no sistemática emergencia, y por esta razón quedan abiertas a la alteración. En lugar de las líneas de determinación dispuestas por las leyes de la historia, la genealogía aparece como un campo de aperturas -defectos, fracturas y grietas. A la inversa, en vez de prometer un cierto futuro, como hace la historia progresista, la genealogía se limita a abrir posibilidades a través de las cuales se pueden perseguir diversos futuros (Brown, 2014, 149).

La escena política, genealógicamente desestabilizada, queda abierta, lo que implica que los términos y la dirección de la lucha política no se pueden anticipar ni cerrar de antemano. La imaginación y la invención son, para Brown, elementos cruciales de la acción política feminista; una política que antes que confrontar directamente el poder, lo desplace, lo conmueva, lo inunde de dinámicas de resistencias corporales, múltiples en sus diferencias. Esta genealogía feminista de Brown posee la fuerza del exceso, en tanto nos empuja a ir más allá de los lugares y conceptos ya sabidos y conocidos, ya formulados y asentados; en cuanto modifica nuestros pensamientos y también nuestros cuerpos, sentimientos, sensibilidades; nuestra procedencia, el presente y nuestro futuro. Foucault nos había arrojado la pregunta:

¿Qué valdría el encarnizamiento del saber si sólo hubiera de asegurar la adquisición de conocimientos y no, en cierto modo y hasta donde se puede, el extravío del que conoce? Hay momentos en la vida en los que la cuestión de saber si se puede pensar distinto de como se piensa y percibir distinto de como se ve es indispensable para seguir contemplando o reflexionando (Foucault, 1993, 12).

Pero es Brown y no Foucault quien dota a esta necesaria interpelación de un alcance feminista. Nosotras, feministas en cuanto al pensamiento y la práctica, con nuestros cuerpos y sensibilidades, sabemos bien que pensar y percibir de un modo distinto al patriarcal y heteronormativo dominante nos es indispensable; en ello nos va la vida. Ya vivimos en riesgo, y así el extravío no es para nosotras una aventura de muerte sino un camino de libertad.

No se trata, sin embargo, de que Foucault no vinculara la filosofía a la política, aunque no fuera su análisis explícitamente feminista. Brown subraya el alcance filosófico y político de la genealogía y la interrelación entre ambos ámbitos, el filosófico y el político. Foucault se opuso a los discursos y prácticas totalizadoras, tanto intelectuales como políticas; él pretendió poner en cuestión supuestas verdades y actitudes autoritarias, que antes que contribuir a revitalizar el pensamiento crítico, persiguen limitarlo e incluso detenerlo por completo. La ontología del presente de Foucault, nos plantea que podría ser diferente a lo que pensamos que es; nos desvía la mirada de aquello que consideramos ya fijado, definitivo, de manera que nos facilita ver de un modo distinto; transforma nuestros presupuestos previos. Este es el trabajo de Foucault que Brown rastrea para alentar el suyo propio en el que la política queda emancipada de la metafísica, de ideales transmundanos, de imperativos divinos o 
de nociones naturalizadas. El campo de lo político que inaugura la genealogía explicita las dinámicas concretas de poder, sus efectos, sus consecuencias; expone los ejercicios de resistencia, percibe las oportunidades para la subversión; da cabida a la contingencia de los deseos y de la imaginación antes que trazar criterios y leyes de obligado cumplimiento. Brown evidencia cómo la política genealógica no acata la perspectiva que exige que las posiciones políticas estén fundamentadas en razonamientos "objetivos" y "sistemáticos"; la política genealógica, al contrario, discurre en alianza con nuestros deseos y apegos.

En este sentido, Nietzsche es recuperado por Brown en tanto fuerza favorable para la práctica democrática. Y su juicio resulta especialmente relevante sobre todo si tenemos en cuenta la habitual ceguera de las interpretaciones, la mayoría, que niegan todo tipo de valor al pensamiento de Nietzsche para la política democrática. La filosofía de Nietzsche derrumba los ideales y metas transcendentes que gobiernan más o menos conscientemente nuestros ejercicios políticos: “ ¿Y si el pensamiento de Nietzsche no hubiera sido hecho para guiar sino para provocar, revelar y desafiar, reforzando de este modo la política democrática?" (Brown, 2014, 180). Brown desvela cómo en las políticas de igualdad y de justicia liberal se esconden sentimientos y motivaciones nunca admitidos, envidias, celos, venganzas. De ahí la importancia de la "genealogía de los deseos" de Nietzsche (Brown, 2014, 181); un ataque a la ignorancia de nuestros deseos. Además, Nietzsche cuestiona también la tendencia de la política moderna hacia la reglamentación y homogeneización de las relaciones humanas y de la actividad de los individuos, ahogando si no eliminando nuestras diferencias y singularidades, nuestra creatividad y nuestra libertad. Bajo ciertas defensas de la igualdad se cobija el poder uniformador y nivelador que no quiere discusión alguna, que no atiende a la multiplicidad de nuestros cuerpos, experiencias y subjetividades; un poder que impone la ley única que dice: te sometes a mi imagen o serás aniquilado. Proyectando el análisis más allá de Nietzsche, en una dirección no formulada por él pero inspirada de algún modo en él, advertimos cómo el orden masculinista y heterosexista exige a las mujeres, disidencias sexuales y subjetividades y corporalidades no normativas, reparar sus diferencias para encajar, o aparentar encajar, en el modelo canónico masculino. En la fábrica de la política, se produce un único uniforme, tejido de misoginia, lesbofobia, homofobia, transfobia, racismo, clasismo; el uniforme del colonizador que te excluye si tu diferencia es tan osada como para querer confeccionar una prenda propia con otras medidas, con otras formas, colores y dibujos.

La crítica de Nietzsche a los fundamentos rígidos nos invita a valorar la vida que se asume en un devenir inquieto sin suelo firme o, en todo caso, con senderos provisionales poblados de argumentos, siempre revisables y revisados, y también de convicciones, ilusiones y emociones, frágiles y oscilantes, conocidas y no conocidas, que nos motivan tanto consciente como inconscientemente. Es la suya una apuesta que pervive en reflexiones actuales sobre la política contemporánea que no renuncian a la dimensión ética de lo político aun cuando subrayan el valor de lo efímero: “Aprender a vivir sin estos apoyos quiere decir a su vez aprender a practicar una conducta ética y perseguir la justicia política dentro de un mundo contingente, imprevisible, no plenamente cognoscible y no dirigido ni por fuerzas exteriores ni por lógicas internas" (Brown, 2014, 205). Brown plantea la utilidad de Nietzsche y de Foucault para el presente, para un presente capaz de alumbrar nuevas posibilidades 
políticas a través de narraciones alternativas que rompan con relatos en los que el pasado se concibe sin fisuras y como causa indiscutible de un presente percibido también sin fracturas.

Retomando a Walter Benjamin, Brown prosigue su análisis sobre cómo pensar y hacer política en las condiciones contemporáneas. La expresión "melancolía de izquierdas" indica el modo en el que la noción moderna de progreso, con sus ideales utópicos, al mostrar su fracaso en el transcurso del tiempo produce una desalentadora sensación de pérdida irrecuperable. Se mantiene un apego perturbador a formaciones del pasado que se añoran que impide que domine el deseo activo de recuperarse de la pérdida dolorosa. De este modo, esta vivencia melancólica obstaculiza el vivir en el presente de una manera libre, no atada al peso del pasado; así que atrapadas y atrapados en nuestras convicciones y en nuestros análisis, disminuimos nuestra atención hacia las situaciones concretas que queremos transformar de nuestro presente. Esta es la diferencia, de acuerdo con Freud, entre el duelo y la melancolía: en el duelo se tiene consciencia de la pérdida; en la melancolía el objeto perdido se mantiene inconscientemente. Brown afirma: "En definitiva, la melancolía de izquierda es el nombre que Benjamin da a un apego -luctuoso, conservador, con la mirada echada hacia atrás- a sentimientos, análisis o relaciones que se han convertido en fetiches, congelados en el corazón del crítico" (Brown, 2014, 237).

No parece desde luego ser este un sentimiento fructífero para la acción política que requiere de un análisis certero del presente con el fin de transformar sus dinámicas misóginas y heterosexistas. Brown no se mantiene en la "melancolía". Incide, por el contrario, en mostrar cómo podemos movilizar la acción política asumiendo la falta de ese proyecto histórico que ya no es el nuestro. No se trata de delinear una distinta concepción del desarrollo histórico sino de activar la conciencia política para posibilitar prácticas de libertad.

En el desarrollo de su reflexión, Brown insiste en subrayar cómo el liberalismo fracasa en lograr aquello que promete. La igualdad, la justicia que anima su discurso y su política, con su pretensión de universalidad, se sostiene, sin embargo, y de un modo interno y no accidental, en una serie de exclusiones, de sexo, género, sexualidad, raza; exclusiones que no se pueden seguir ignorando. El sujeto liberal se nos ha desvelado y hay que continuar explicitándolo porque todavía su palabra dice ser expresión de toda palabra humana: es masculino, blanco, heterosexual, burgués, occidental; es un sujeto que, además, tiene implicaciones normativas que solo protegen a las familias heterosexuales, patriarcales, blancas, capitalistas. Su Estado, el del liberalismo, y su cultura, que encumbra a un sujeto abstracto, desprovisto de cuerpo y de relaciones sociales específicas, es una ficción imposible y, más aún, peligrosa en cuanto esconde que su poder se organiza y se lleva a efecto a través de la subordinación y de la opresión. No hay un futuro en el que el liberalismo alcance su meta proclamada de igualdad y libertad universales porque el liberalismo se articula a partir de esa noción de sujeto en sí profundamente problemática. ¿Cuál será entonces la acción de nuestra política feminista?: "construir desafíos políticos vitales y vibrantes a las prácticas actuales de falta de igualdad y de libertad sobre la base de críticas y objetivos parciales, y no totalizadores; sobre la base de un pensamiento político provisional y estratégico, y no milenarista y teleológico" (Brown, 2014, 34-35).

En su trabajo “Women's Studies Unbound: Revolution, Mourning, Politics" (Brown, 2003), alude a que el feminismo contemporáneo se distancia de la fe propia de la modernidad en la capacidad de la revolución feminista para eliminar por completo la desigualdad y 
para alterar absolutamente todas las relaciones sociales misóginas. Pero lo importante para Brown es que lo perdido no es la misma idea de revolución sino la concepción de lo humano como sujeto dotado de un control completo sobre sí y sobre sus semejantes; la creencia en que ese sujeto liberal puede alcanzar aquello que promete: igualdad y libertad universales. Si eso es lo perdido, no hay que lamentarlo, al menos no desde la posición feminista postestructuralista.

Son dos los sueños de revolución ya no soñados, según Brown: la revolución socialista, por un lado, y la feminista y sexual, por otro lado. Desde la perspectiva particular de la revolución feminista moderna, se luchaba por la igualdad de las mujeres y de los hombres, pero no únicamente, ni mucho menos. Su alcance y su horizonte fueron extensos y radicales. Se trataba de reformular el parentesco, el orden de lo público y privado, el ámbito del deseo y la sexualidad, el espacio de lo psíquico, de la subjetividad; la vida en su cotidianidad, en lo cercano y próximo y no solo lo que atañe a la esfera de lo legal, jurídico, institucional. Un más allá del género, en tanto género se entendía como relación de subordinación de las mujeres y de lo femenino, fue proyecto del feminismo moderno: un mundo imaginado en ausencia radical de dominación.

Este impulso feminista, Brown lo percibe en el feminismo de la llamada segunda Ola, años 60, 70 y 80; y también rastrea sus huellas en el feminismo activo en la revolución francesa y rusa y en autoras como Mary Wollstonecraft. Si el comunismo defendía un futuro sin clases sociales y sin ningún signo de dominación, ese feminismo imaginaba un mundo sin relaciones sociales de opresión. La figura de la androginia fue allí relevante pero otras versiones se dirigían hacia la expresión de las diferencias en libertad, sin sometimientos ni jerarquizaciones. Brown se pregunta cómo sería el feminismo sin estos ideales por mucho que puedan ser considerados como ingenuos en algún sentido, y por más que hayan mostrado su no realización material y efectiva, por el momento, al menos. El feminismo denuncia los abusos del poder misógino y heterosexista, cuestiona las normas que oprimen y victimizan a las mujeres. El feminismo, antes y hoy, es sobre todo revolución transformadora que implica a todos los ámbitos y espacios del mundo de la vida.

No obstante, si bien Brown argumenta a favor del ánimo revolucionario como energía presente en los feminismos contemporáneos, esto no es lo mismo que afirmar que permanecen idénticos los ideales utópicos de la modernidad. Retener los sueños modernos genera el sentimiento melancólico que ella considera que debilita la fuerza transformadora propia del feminismo. La melancolía nos entristece y nos desalienta sin saber del todo cómo y por qué nos embarga el pesimismo, dado que es en buena medida una emoción inconsciente. En el marco feminista postestructuralista, el proyecto moderno ha quedado desarticulado; aquí no opera la melancolía sino el duelo, el reconocimiento de la pérdida que despeja el terreno y potencia la apertura en nuevas direcciones, provistas de otros instrumentos, provisionales, contingentes.

El feminismo de Brown, no plantea la eliminación del género en el sentido revolucionario moderno y no por ello deja de ser un feminismo vivo, ágil, dinámico; al contrario, es un feminismo atento a las condiciones de nuestro presente, que sabe analizarlas y que a partir de ahí, de su habilidad para señalar y para describir los problemas que nos rodean y que nos afectan, nos provee de estrategias lúcidas para desbaratar la misoginia y el heterosexismo más agudo que padecemos. En su línea de pensamiento, el género no se 
aniquila, se concibe de otro modo y se diversifica en múltiples sentidos; enfoca el análisis, compartiendo puntos de vista con Butler, en cómo el poder de dominación inscrito en el género genera subjetividades subversivas, resistentes al poder opresivo desde su interior mismo. En una matriz de género, por así decirlo, habitamos; no podemos, al menos no ahora, escapar del género, de las normas de género que nos habilitan, pero sí es posible la dislocación de sus dinámicas, apropiarnos del género en versiones que motiven nuestros deseos en lugar de estigmatizarlos. No vivimos fuera del género, en un lugar externo donde fuera factible la resistencia de un sujeto que pudiera contraponerse al género desde el exterior del género mismo. La persona abstracta pensada por la modernidad ya ha mostrado lo que oculta: anhelos de control soberano, soberbia, prepotencia masculina, blanca y heterosexual. El lenguaje aquí no es el de la emancipación del género; es el de la resignificación, subversión, innovación.

Brown nos orienta en una dirección en la que se derrumban los fundamentalismos, los ideales de conocimiento pleno, de perfección absoluta, de un mundo sin fisuras y, al mismo tiempo, revitaliza el impulso utópico, el deseo de transformación. Se trata de aceptar la pérdida de la promesa crítica moderna pero reconociendo que esta promesa nos ha formado de algún modo; tanto la utopía como su muerte, ambos elementos, constituyen el lugar de nuestra subjetividad contemporánea. Un lamento paralizante no es ni la única ni la más valiosa consecuencia de la pérdida. El reto está en reflexionar sobre qué aspectos particulares de los ideales de la modernidad podrían reconfigurarse como fuerzas vivas en nuestro presente. Sobre el suelo de lo perdido, que es el nuestro, el que nos ha configurado, no ningún otro distinto, nos aventuramos a lo nuevo, a lo todavía no conocido, con imaginación, con nuestra fantasía, con nuestras emociones, nuestros cuerpos y diferencias.

El duelo da paso en Brown a una forma postrevolucionaria fecunda, a una sensibilidad política que halla su productividad en el campo de un cierto no saber, sin certezas absolutas sobre sus proyectos y sobre la viabilidad de su realización. Lo posible no se cierra, palpita abierto a lo imprevisible porque desconocemos de qué somos capaces y desde ahí nos damos una oportunidad para el vuelo de la creatividad.

En otro de sus textos, "El deseo de amurallar" (Brown, 2015), Brown también investiga los efectos sociales, políticos y psíquicos de la melancolía y del duelo; realiza una inteligente crítica a la en nuestros días constatable proliferación de muros y fronteras, en sentido tanto político como psíquico e identitario. Los muros fracasan escandalosamente en su intento de recuperar la soberanía, autonomía, control absoluto, la potencia bélica masculina que la modernidad había prometido; los muros parecen responder a un anhelo psíquico de seguridad, pero los muros son potentes mecanismos literales y simbólicos de producir violentas exclusiones.

Los cuerpos masculinos como cuerpos amurallados remiten a una imagen de cuerpos prepotentes y autosuficientes que el feminismo cuestiona por sus efectos perversos. Adriana Cavarero, en "Inclinaciones desequilibradas" (Cavarero, 2014), trae a escena metáforas geométricas de lectura feminista: la verticalidad, la horizontalidad y la inclinación. La verticalidad remite al sujeto en pie, derecho, recto; es el sujeto agresivo de Hobbes y el sujeto autónomo, libre, racional de Kant, quien diferencia la infancia de este cuerpo adulto masculino contrario a la inclinación, a la inclinación de la madre hacia la niña y el niño. La inclinación del cuerpo sugiere un modo feminista de pensar la vulnerabilidad que se distan- 
cia tanto de la verticalidad masculina como de la horizontalidad que nombra el espacio de la igualdad liberal que formula la ontología individualista y descorporalizada; un espacio en el que se presupone que todo individuo adopta la postura erguida negando el cuerpo y su precariedad así como las diferencias entre los cuerpos: cuerpos dominantes y dominadores, cuerpos marginados y minusvalorados en cuanto feminizados.

Si bien tampoco podemos negar, pensando con Butler, que no se cumplen siempre las expectativas de las categorías: hay inclinaciones que son masculinas y verticalidades femeninas (Torras y Gama, 2014, 117). Los marcos culturales no son rígidos ni inmóviles, no hay que dotarlos de un poder absoluto; son transformables, los alteramos. Lo dicho no impide, no obstante, que las políticas de la vulnerabilidad corporal defendidas por Butler con gran intensidad y constancia a lo largo de sus obras y con voluntad, precisamente, de ofrecer un ámbito de intelección que nos permita romper con la representaciones y percepciones misóginas y heterosexistas, no pongan en evidencia cómo lo que llamamos feminidad y masculinidad es producto de la distribución desigualitaria e injusta de la vulnerabilidad. La masculinidad se define, en los contextos misóginos y heterosexistas, por su invulnerabilidad e impenetrabilidad y la feminidad, en direcciones antifeministas, por su vulnerabilidad y penetrabilidad.

El cuerpo en su vulnerabilidad, y no el ser humano racional, retiene la mirada de Butler. El cuerpo es constitutivamente, y no accidentalmente, vulnerable en cuanto se articula en relaciones de interdependencia, en un sentido físico, emocional y también social y político:

Creo que si nos centramos en el cuerpo podemos pensar sobre la interdependencia de un modo distinto. Podemos empezar con el cuerpo del bebé, que no puede sobrevivir sin el cuidado físico de otra persona y cuya dependencia física de otro ser humano determina si sobrevivirá o no. Cometemos un error si creemos que el paso de la infancia a la madurez implicar lograr una independencia que nos libera de esa interdependencia. Los adultos seguimos dependiendo de los otros para nuestra supervivencia (Butler, 2011, 58).

En Marcos de guerra (Butler, 2010), el cuerpo continúa siendo el lugar privilegiado de sus argumentaciones. Allí se concentra en delinear una nueva ontología corporal que es a la vez una ontología social de dimensiones éticas y políticas. Escribe Butler:

Hablar de "ontología" a este respecto no es reivindicar una descripción de estructuras fundamentales del ser distintas de cualquier otra organización social o política. Antes al contrario, ninguno de estos términos existe fuera de su organización e interpretación políticas. El "ser" del cuerpo al que se refiere esta ontología es un ser que siempre está entregado a otros: a normas, a organizaciones sociales y políticas que se han desarrollado históricamente con el fin de maximizar la precariedad para unos y de minimizarla para otros. No es posible definir primero la ontología del cuerpo y referirnos después a las significaciones sociales que asume el cuerpo. Antes bien, ser un cuerpo es estar expuesto a un modelado y a una forma de carácter social, y eso es lo que hace que la ontología del cuerpo sea una ontología social (Butler, 2010, 15). 
El cuerpo no es una realidad dada previamente, de naturaleza incontestable, aislada e independiente del orden social; es más una relación que una entidad. El cuerpo se conforma con otros cuerpos, en una atmósfera espacial y temporal que fluye, deviene; en un terreno que está organizado de acuerdo con un marco normativo que habilita y permea al cuerpo, pero no de un modo pasivo y sumiso, porque el cuerpo a la vez actúa y en su acción modifica, desplaza las normas que le dan cobijo. Desde esta situación de interdependencia insalvable mas afirmada como nuestra posibilidad de potenciar vínculos transformadores, Butler denuncia el ejercicio político que distribuye de manera jerarquizadora y desigualitaria nuestra vulnerabilidad constitutiva y existencial. No la vulnerabilidad que somos sino el uso, y abuso, político de la precariedad es lo que Butler visibiliza y enfrenta, porque conlleva el aumento de precariedad a cuerpos feminizados, racializados, insumisos a la ley heterosexual, con el objetivo de reducir la precariedad a los cuerpos normativos masculinizados. La precariedad compartida es lo que caracteriza a esta ontología corporal y social que Butler defiende y a la que otorga el valor prometedor de impulsar nuestro pensamiento y nuestra sensibilidad en una dirección en la que la vida pueda ser vivida en condiciones de igualdad y de libertad, sin excluir las vidas de las corporalidades estigmatizadas o infravaloradas, como las de las mujeres y lesbianas.

En alianza, ocupan las calles con demandas políticas, se extienden por las plazas, en los espacios abiertos, públicos; cómo se compartan los cuerpos y se acercan unos a otros, en las situaciones más íntimas, diarias y cotidianas, fuera ya del escenario, sin cámaras y micrófonos (Butler, 2012); detener ahí la mirada importa porque entonces será cuando constatemos si el entrelazamiento de los cuerpos sucede al margen de misoginia y heterosexismo: si estos son cuerpos feministas en revolución. La pérdida contemporánea de la versión ilustrada de revolución, de la que nos hablaba Brown, no exige en absoluto la compulsión hacia la construcción de muros tras los que esconder nuestra dañabilidad y dependencia. Dejar atrás la noción de sujeto soberano, sin cuerpo, sin necesidades orgánicas ni materiales, no debilita ni paraliza necesariamente la acción política subversiva. Despeja el horizonte de la pesada densidad del orden masculinista para incentivar luchas parciales, contextuales y provisionales, desde el reconocimiento de la vulnerabilidad de nuestros cuerpos y, por ello, con capacidad para la afirmación feminista.

Resistir no la vulnerabilidad, sino resistir desde la vulnerabilidad. Una interrelación inusual entre ambos conceptos es lo que acentúa Butler en su trabajo "Repensar la vulnerabilidad y la resistencia" (Butler, 2014). Los cuerpos exponen su vulnerabilidad como forma específica de oposición no a su precariedad constitutiva sino a la precariedad inducida políticamente. Reclaman que sin las condiciones materiales y simbólicas adecuadas; sin redes de apoyo y de relaciones, como cuerpos interdependientes que somos no es posible vida alguna. Somos sujetos corporales expuestos, susceptibles de ser afectados y en ese sentido vulnerables. Las políticas performativas de Butler son políticas corporales feministas que trabajan para desbaratar la presión coercitiva que las normas de género, sexo, sexualidad, y las instituciones que las sostienen y reproducen, ejercen sobre nuestras vidas; sin ellas, sin las normas, en cierto sentido no somos ya que dependemos de ellas desde el principio y en todo momento; pero en ellas, en otros aspectos, nuestros cuerpos y nuestras psiques habitan en la opresión y estigmatización. La vulnerabilidad nombra nuestra receptividad y con ella nuestra capacidad de respuesta. Desde la visibilización y el reconocimiento de esta 
vulnerabilidad nuestra actuamos políticamente en contra del núcleo misógino, lesbófobo, tránsfobo, racista, que nos hace y nos deshace. Si la norma masculinista de lo humano se cierra en torno al ideal de independencia, la política feminista afirma la interdependencia de los sujetos corporizados.

\section{Referencias bibliográficas}

Brown, Wendy (2003): “Women's Studies Unbound: Revolution, Mourning, Politics”, Parallax, vol. 9, número 2, pp. 3-16.

Brown, Wendy (2014): La política fuera de la historia, Enclave de Libros, Madrid (edición original de 2001).

Brown, Wendy (2015): "El deseo de amurallar", en Wendy Brown, Estados amurallados, soberanía en declive, Herder, Barcelona, pp. 155-194.

Butler, Judith (2010): Marcos de guerra. Las vidas lloradas, Paidós, Madrid.

Butler, Judith (2011): "Las categorías nos dicen más sobre la necesidad de categorizar los cuerpos que sobre los cuerpos mismos". (Entrevista de Daniel Gamper Sachse), en Judith Butler, Judith Butler. Violencia de Estado, guerra, resistencia. Por una nueva política de la izquierda, Katz Editores, Madrid, pp. 47-81.

Butler, Judith (2012): "Cuerpos en alianza y la política de la calle", Revista Trasversales, número 26.

Butler, Judith (2014): "Repensar la vulnerabilidad y la resistencia", conferencia impartida en Alcalá de Henares en junio de 2014, en el XV International Association of Women Philosophers Symposium. Philosophy, Knwoledge and Feminist Practices.

Cavarero, Adriana (2014): "Inclinaciones desequilibradas", en Begonya Saez Tajafuerce (ed.), Cuerpo, memoria y representación. Adriana Cavarero y Judith Butler en diálogo, Icaria, Barcelona, pp. 17-38.

Foucault, Michel (1993): Historia de la sexualidad. 2. El uso de los placeres, Siglo veintiuno, Madrid.

Torras, Meri y Michelle Gama Leyva (2014): "Un diálogo entre Judith Butler y Adriana Cavarero (itinerario de resonancias)", en Begonya Saez Tajafuerce (ed.), Cuerpo, memoria y representación. Adriana Cavarero y Judith Butler en diálogo, Icaria, Barcelona, pp. 99-120. 